\title{
The rationale and evidence for virtual methods of training for caregivers: A narrative review
}

\author{
Pinky Budhrani-Shani ${ }^{1}$, Nisha J Mathews ${ }^{2}$
}

\begin{abstract}
Citation: Shani PB, Mathews NJ. The rationale and evidence for virtual methods of training for caregivers: A narrative review. J Nurs Res Pract. 2020;4(2): 01-06.

BACKGROUND: Caregiver (CG) burden has been a growing concern among informal CGs. CG burden has a significant impact on CGs' health and wellbeing. This paper summarizes prevalence of burden among CGs, mind-body exercises for caregivers, gaps in the current evidence, effects of telehealth-based interventions, limited access and barriers to the widespread use of mind-body interventions for CGs, and strengths and limitations of this review.
\end{abstract}

METHODS: Articles, published from 2014 and 2020, were included in the review using PubMed/MEDLINE, Web of Science, and Science Direct articles. Search terms were caregiver, intervention, burden, mind-body, online, and/or internet.
We included experimental, quasi-experimental, descriptive, cross sectional, exploratory, and intervention study designs. Data synthesis included narrative and tabular summary of results.

DISCUSSION AND CONCLUSION: The review highlighted the high prevalence of CG burden of informal CGs of demanding diseases. This review suggests the importance of doing further research on CG burden of informal CGs and its impact on their health and evaluating the effect of web based and telehealth interventions for informal CGs of demanding diseases. Additional research is needed to further enforce the link between CGs burden and effective interventions using telehealth and web-based platforms.

Key words: Caregiver; Intervention; Burden; Mind-body; Online; Internet

\section{INTRODUCTION}

$\mathrm{L}$ onger life expectancies and an aging population mean that an increasing number of adults are likely to develop multiple comorbidities and rely on informal caregivers (CGs) for support [1,2]. Informal CGs, typically family members or friends, are responsible for caring for individuals with a variety of burdensome conditions including advanced age, dementia, and cancer. In addition to providing psychological support, CGs are also commonly responsible for relatively complex medical procedures, despite limited or no formal training, as well as taxing physical support (e.g., weight transfers, increased household chores). Collectively, these responsibilities result in substantial and chronic stress, with adverse psychological and physiological effects on CGs' health [3-5]. CG burden has even been identified as an independent predictor of caregiver mortality with a $63 \%$ increased risk of death.6 Additionally, research indicates that decreased CG quality of life (QOL) directly impacts the QOL of care recipients [6-8].

Prevalence of burden among caregivers

In recent years, a growing body of literature has supported the argument that family CGs take on a significant burden when caring for people with severe diseases, such as musculoskeletal problems, Alzheimer's disease, dementia, stroke, heart failure, and cancer [9]. Increasing stress due to longer duration of caregiving produces marked changes in the neurohormonal and inflammatory process, which may increase the risk of morbidity and mortality among CGs [10]. CGs' time and effort, use of material and emotional resources, and social life compromise reduces CGs' QOL [11,12]. Approximately $62 \%$ of CGs sustain high burdens and spend approximately 33 hours weekly with patients, which may involve complicated medical or nursing assignments for as much as $72 \%$ of CGs $[13,14]$. It has been reported that the mental health of the CGs is disrupted more seriously than physical health [15]. As per the study findings, the prevalence of anxiety and depression in cancer patient CGs is high, and the quality of life of CGs is low [16]. Moreover, the presence of cancer itself is a dominant source of depression and anxiety in CGs, and several other factors may exaggerate the symptoms. These include relationship and communication between caregivers and patient, CGs' social, economic, and psychological attributes, CGs' health, and caregiving duration. As CGs are at high risk of disease, appropriate interventions targeting their psychosocial, physical, and mental health needs are required to reduce this risk. Therefore, there is a pressing need to develop effective and practical interventions to prevent and manage the psychological and physical stressors that reduce QOL in CGs.

The burden experienced by CGs is complex and best viewed through a biopsychosocial framework

CG burden is defined as "the extent to which CGs perceive that caregiving has had an adverse effect on their emotional, social, financial, physical, and spiritual functioning" [17]. This definition emphasizes the multidimensional and biopsychosocial complexity of caregiving $[18,19]$. Examples of psychosocial symptoms experienced by CGs include increased anxiety, depression, isolation, lack of social support, helplessness, loss of control, and fear of recurrence [20-23]. More behavioral and somatic concerns include lack of exercise, poor sleep, fatigue, weight gain or loss leading to impaired immune system function, coronary heart disease, and early mortality [24-27]. CGs of both older children and adult patients also report a significantly higher prevalence of musculoskeletal pain, attributed to lifting and transferring heavy loads $[28,29]$, paralleling load-related problems widely reported by CGs based in medical settings [23]. From a biospychosocial perspective, these symptoms are highly interdependent. For example, poor sleep and chronic fatigue are known to contribute to the risk of depression, and depression and chronic pain are both linked to common inflammatory pathways [30]. This interdependent constellation of symptoms underlying CG distress has led to exploration of integrative, multi-modalmind-body interventions that can address a range of psychosocial and physical concerns [31-33].

\section{Mind-body exercises for caregivers: Gaps in the current evidence}

Mind-body practices that target both psychological and physical dimensions of distress offer a promising and pragmatic therapeutic strategy for addressing the needs of CGs $[23,34,35]$. However, the evidence required to guide such an approach is still limited in multiple ways. First, while a growing body of research supports mind-body practices such as Tai Chi, Qigong, yoga, and meditation for a range of symptoms in patients with chronic disease, only a few large-scale studies have evaluated the impact of these practices in CGs. Of the studies which have evaluated CGs (mostly yoga or MBSR), many have utilized interventions tailored to patient-CG dyads [36-44]. Altough this approach has merit, it may limit targeting CGs psychological and physical

${ }^{1}$ Department of Nursing, College of Nursing, Houston, Texas Woman's University, Texas, USA; ${ }^{2}$ Department of Nursing, San Jacinto Community College Central, Pasadena, Texas, USA

Correspondence: Pinky Budhrani-Shani, Assistant Professor, Department of Nursing, College of Nursing, Houston, Texas Woman's University, Texas, USA, Tel: +713-794-2193; e-mail: pbudhrani@twu.edu

Received: March 04, 2020, Accepted: April 02, 2020, Published: April 10, 2020

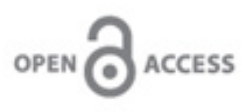

OPEN $\bigcirc$ ACCESS

This open-access article is distributed under the terms of the Creative Commons Attribution Non-Commercial License (CC BY-NC) (http:// creativecommons.org/licenses/by-nc/4.0/), which permits reuse, distribution and reproduction of the article, provided that the original work is properly cited and the reuse is restricted to noncommercial purposes. For commercial reuse, contact reprints@pulsus.com 
needs. Additionally, more widespread access to mind-body interventions targeting CGs has been challenged by economic, geographic, and time barriers. Common barriers to in-person group classes (e.g., issues with CG travel to community-based programs) might be overcome with internetbased delivery of the intervention, offering an alternative for some CGs that may significantly increase access and adherence. While internet delivery of individual-based mind-body practices is increasingly studied and shows promise, this approach has not been explored in CG populations [45].

Limited access and barriers to the widespread use of mind-body interventions for caregivers

A critical challenge in implementing any intervention is the practical issue of adherence $[7,46,47]$. Prior studies, ranging from exercise, psychotherapy, to medication, show low adherence $[7,47,48]$. In the case of mind body interventions, one possible solution is internet or virtual delivery of instruction. This approach would address the broad issue of access to evidence-based programs, especially of concern in non-metropolitan/rural areas where mind-body interventions are not available. It would also provide an alternative option for CGs who cannot leave home, and/or allocate the time required to travel to and from regular classes. Of note, an analysis of the 2012 National Health Interview Survey data indicates that a significant proportion of the US population that report using interventions for health preferred self-directed learning from DVDs and internet resources [49]. The large and growing market for self-directed learning programs substantiates this finding, and also highlights the need to evaluate the safety and efficacy of this mode of delivery.

While a handful of studies support the potential for web-based or DVDbased learning of mind-body practices, evaluations of such programs have not been well tested, especially in CGs. In a small feasibility study, Wu and Keyes delivered a 15-week long Tai Chi program for older balance-impaired individuals using an internet-based live video-conferencing platform [50]. They reported proper compliance (average 78\%), comfort with navigating technology, and high interest in ongoing training. They also reported meaningful improvements in balance and physical function. A followup study compared the effectiveness of Tai Chi delivered via live videoconferencing, in-person community-based classes, and home-based selfdirected video learning [51]. While all three groups showed trends towards improvements in QOL and multiple measures of balance and function, protocol adherence and improvements were lowest in the self-directed video learning group. Promising trends, but relatively low compliance and high dropout rates were also reported in another feasibility study evaluating a video-guided Tai Chi program for older adults for balance [47]. Collectively, these studies support the promise of mind-body exercise classes being offered in the home, but perhaps suggest that at least some contact and support from instructors may be critical for obtaining higher levels of adherence.

\section{LITERATURE REVIEW}

Electronic literature searches were conducted using PubMed/MEDLINE, Web of Science, and ScienceDirect articles published from 2014 and 2019. Search terms were caregiver, intervention, mind-body, online, and/ or internet. The inclusion criteria were studies that included web based intervention/internet-based intervention for CGs; only applicable for CGs; CGs of individuals 18 years or older; and studies published in last five years. The exclusion criteria were studies with no results, and studies involving children. Title and abstract and full text screening were completed in duplicate. Data were extracted by a single reviewer and verified by a second reviewer.

\section{RESULTS AND DISCUSSION}

The search yielded 50 unique citations, of which 46 studies were screened at full- text. Of those, only nine studies met the inclusion criteria. Five studies were experimental designs, three studies were descriptive designs, and one study was a pilot randomized controlled trial. The review included a total number of 1,585 caregivers ( $n=1,585$ participants). The studies included in the review ranged from year 2015 to year 2019. There was variability of effects across most outcomes. Risk of bias could not be fully assessed. The Review of Literature table includes authors, years, study design, sample, intervention, control, assessment, measures, and physical measures used in the selected studies.

\section{Caregiver burden}

One of the main findings concluded from the table was the high prevalence of caregiver burden among CGs of burdensome diseases and the importance of mind-body exercises intervention in improving the $\mathrm{QOL}$ of caregivers.
Caregiver's training, socioeconomic support especially for women and healthcare support can improve the quality of caregiving as well as quality of life of caregivers [52]. Rha, Park, Song and Lee, suggested that caregiving burden as the influential factor which negatively affected the QOL. The family CGs of cancer patients reported experiencing a moderate level of caregiving burden, although about one-quarter of them reported a high caregiving burden [53].

\section{Promise of tele- mind-body}

E-health interventions potentially enhance the quality of care and reduce health care costs. It may do so by providing patient education and counselling for primary prevention and early detection of disease, replacing face-to-face visits with health care professionals, collecting patient data on medical parameters remotely, among several other mechanisms [12,13,54-56]. Research-tested interventions delivered to CGs of patients with cancer or other chronic illnesses can reduce many of these negative effects and improve CGs' coping skills, knowledge, and quality of life. But these interventions are seldom implemented in practice [57]. Systematic reviews revealed many promising effects of e-health interventions along with larger claim trials to confirm the clinical effects of home tele-monitoring [58]. These include internet-based device-assisted remote monitoring systems in patients with cardiovascular implantable electronic devices, technology-assisted training and support programs for family members of patients with traumatic brain injury, and web-based education to increase patient empowerment $[59,60]$.

Paré and colleagues assessed the clinical effects of home tele monitoring in patients with a variety of chronic diseases. The authors highlight the fact that home tele monitoring allows for closer follow-up of individual patients' conditions [61]. Kaskinen and colleagues offered information about pediatric physician-led web-based chat services, which may provide an easy e-consultation channel for caregivers with a variety of concerns about their child's health or illness [62]. Both CGs and physicians considered that the concerns of CGs were well handled, and the vast majority of CGs' questions could be well answered in a web-based chat. Thus, a pediatric web-based chat service provided for CGs of children may be a useful way to help CGs with concerns about their child's health or illness. All chat consultations were initially responded to within 15 minutes of the first message from the CG, and the average response time was five (SD 2) minutes [61-63].

A study by Lappalainen, Pakkala, and Nikander compared the effectiveness of a novel web-based program in reducing depressive symptoms and improving the psychological well-being of elderly family caregivers. If successful, the study would yield information on the persons for whom these interventions would be most beneficial, and what mechanisms mediate the intervention effects [64]. A study by Tan et al., showed most participants exhibited a stable trajectory of change in their QOL, while a small number of participants either improved or declined. The study emphasized that understanding the sustainability of the effects of the intervention is essential in determining the need to initiate periodic "booster" sessions to provide consistent support for CGs [65].

Sahadevan and Namboodiri cross sectional study showed more than half of the patients' relatives spent above 10 hours per day in caregiving $(n=259$ [67\%]). Only one-fifth of the patients required the relative's assistance for their personal care $(n=69[18 \%])$. However, half of the principal CGs had to do domestic chores at home, along with caregiving ( $\mathrm{n}=192$ [50\%]). Exactly half of the principal CGs also provided financial support for the treatment $(\mathrm{n}=192$ [50\%]). The majority of the principal caregivers had depression $(n=202[52.5 \%])$. Among those who had depression, the majority had mild depression $(\mathrm{n}=134[35 \%])$, and sixty-one (16\%) had moderate depression. Only a small portion of them had severe depression $(n=7$ [2\%]) [66].

\section{Effects of virtual reality}

Lotan, Yalon-Chamovitz, and Weiss (2011) sought to present and evaluate the feasibility of an educational program that enabled the implementation of a virtual reality (VR) program operated by in-house CGs for adults at a severe level of IDD [67]. The focus groups' results showed that the overall involvement in the VR program was beneficial to both staff members and participants alike. According to reports by CGs, participation in the selected virtual games, with their associated physical and cognitive demands, was found to be motivating for many but not all participants. Integrating a VR program as part of the routine schedule of a residential facility was found to be feasible and beneficial for participants and staff members alike. The strategy used to enable the implementation of a VR program by in-house caregivers was shown to be feasible. The VR intervention program promoted activity and was motivating to and enjoyable by all participants with mild to moderate IDD and to most individuals with severe IDD. Significant $(\mathrm{P}<.05)$ 
Budhrani-Shani P, et al.

Review of Literature table:

\begin{tabular}{|c|c|c|c|c|c|c|c|}
\hline Authors/Year & Study Design & Sample & Intervention(s) & Control & Assessments & Measures & $\begin{array}{l}\text { Physical } \\
\text { Measures }\end{array}$ \\
\hline $\begin{array}{c}\text { Lappalainen, } \\
\text { Pakkala, Nikander/ } \\
\text { March } 2019\end{array}$ & $\begin{array}{l}\text { quasi- } \\
\text { experimental } \\
\text { controlled } \\
\text { trial }\end{array}$ & $\begin{array}{c}\mathrm{n}=156 \text { caregivers age } \\
\geq 60 \text { years } \\
\mathrm{n}=65 \text { caregivers } \\
\text { receiving a guided } \\
12 \text { week web-based } \\
\text { intervention } \\
\mathrm{n}=52 \text { caregivers } \\
\text { in rehabilitation } \\
\text { program }\end{array}$ & $\begin{array}{l}\text { - } 12 \text { week web- } \\
\text { based intervention } \\
\text { - Standardized } \\
\text { institutional } \\
\text { rehabilitation } \\
\text { program in a } \\
\text { rehabilitation } \\
\text { center }\end{array}$ & $\begin{array}{l}\text { Receiving } \\
\text { support from } \\
\text { voluntary } \\
\text { family } \\
\text { caregiver } \\
\text { associations. }\end{array}$ & $\begin{array}{l}\text { • Beginning of } \\
\text { the study (pre- } \\
\text { measurement) } \\
\text { - } 4 \text { months (14 } \\
\text { weeks after pre- } \\
\text { measurement) } \\
\text { - } 10 \text { months (post- } \\
\text { measurement) }\end{array}$ & $\begin{array}{c}\text { • BDI-II } \\
\text { • COPE } \\
\text { - WHOQOL-BREF } \\
\text { • GAD-7 } \\
\text { - SOC-13 } \\
\text { - AAQ-II } \\
\text { - EACQ } \\
\text { - WBSI } \\
\text { - S5 } \\
\text { - SPPB }\end{array}$ & $\begin{array}{l}\text { - Balance, } \\
\text { - } 4 \text { m walking } \\
\text { - Chair rising }\end{array}$ \\
\hline $\begin{array}{l}\text { Bijker, Kleiboer, } \\
\text { Riper, Cuijpers, } \\
\text { Donker } \\
\quad \text { Sept. } 2017\end{array}$ & $\begin{array}{l}\text { pilot } \\
\text { randomized } \\
\text { controlled } \\
\text { trial }\end{array}$ & $\begin{array}{c}\mathrm{n}=80 \text { caregivers of } \\
\text { depressed patients } \\
\mathrm{n}=41 \text { caregivers } \\
\text { receiving e-care }\end{array}$ & $\begin{array}{c}\text { - E-care for } \\
\text { caregivers: a series } \\
\text { of self-help modules } \\
\text { for caregivers } \\
\text { of depressed } \\
\text { individuals }\end{array}$ & $\begin{array}{l}\text { waitlist- } \\
\text { control group }\end{array}$ & $\begin{array}{l}\text { - Baseline } \\
\text { (beginning of the } \\
\text { study) } \\
\text { - } 6 \text { weeks (post- } \\
\text { intervention) } \\
\text { - semi-structured } \\
\text { phone interview } \\
\text { to assess user- } \\
\text { friendliness of } \\
\text { intervention }\end{array}$ & $\begin{array}{c}\bullet \text { SUS } \\
\bullet \text { K10 } \\
\bullet \text { GAD-7 } \\
\text { - Dutch version of the } \\
\text { Zarit Burden Interview } \\
\text { • EQ5D } \\
\text { - Pearlin Mastery Scale } \\
\text { - telephone interviews }\end{array}$ & $\mathrm{N} / \mathrm{A}$ \\
\hline $\begin{array}{l}\text { Tan, Lam, Lim, } \\
\text { Kua, } \\
\text { Griva, Mahendran/ } \\
\text { December } 2017\end{array}$ & $\begin{array}{l}\text { quasi- } \\
\text { experimental } \\
\text { study design }\end{array}$ & $\begin{array}{c}\mathrm{n}=56 \text { Caregivers of } \\
\text { patients attending an } \\
\text { outpatient clinic at a } \\
\text { cancer center }\end{array}$ & $\begin{array}{l}\text { This group } \\
\text { intervention } \\
\text { comprised four } \\
\text { weekly sessions } \\
\text { simultaneously } \\
\text { targeting } \\
\text { psychoeducation, } \\
\text { skills training, and } \\
\text { supportive therapy. }\end{array}$ & $\begin{array}{l}\text { waitlist- } \\
\text { control group }\end{array}$ & $\begin{array}{l}\text { - baseline } \\
\text { - immediately post- } \\
\text { intervention } \\
\text { - } 4 \text { weeks after } \\
\text { intervention } \\
\text { - } 8 \text { weeks after } \\
\text { intervention }\end{array}$ & $\begin{array}{l}\text { - Caregiver QOL- } \\
\text { Cancer scale }\end{array}$ & $\mathrm{N} / \mathrm{A}$ \\
\hline $\begin{array}{c}\text { Sahadevan, \& } \\
\text { Namboodiri/2019 }\end{array}$ & $\begin{array}{l}\text { cross-sectional } \\
\text { study }\end{array}$ & $\begin{array}{l}\mathrm{n}=384 \text { caregivers of } \\
\text { patients with breast } \\
\text { cancer }\end{array}$ & $\begin{array}{c}\text { Interviews and } \\
\text { Questionnaire Tests }\end{array}$ & $\begin{array}{l}\text { no control } \\
\text { group }\end{array}$ & & $\begin{array}{l}\bullet \text { ICD-10 used to } \\
\text { diagnose depression } \\
\text { - (HAM-D) used to } \\
\text { measure the severity } \\
\text { of the symptoms Chi- } \\
\text { square test and Fisher's } \\
\text { exact test used to find } \\
\text { association between } \\
\text { symptoms of depression }\end{array}$ & $\mathrm{N} / \mathrm{A}$ \\
\hline $\begin{array}{l}\text { Lim, Tan, Chua, } \\
\text { Yoong, Lim, Kua/ } \\
\text { May } 2017\end{array}$ & $\begin{array}{l}\text { exploratory } \\
\text { study }\end{array}$ & $\begin{array}{c}\mathrm{n}=258 \text { family } \\
\text { caregivers of cancer } \\
\text { patients }\end{array}$ & $\begin{array}{l}\text { Sociodemographic } \\
\text { questionnaire, } \\
\text { CQOLC }\end{array}$ & $\begin{array}{l}\text { no control } \\
\text { group }\end{array}$ & & - CQOLC & $\mathrm{N} / \mathrm{A}$ \\
\hline $\begin{array}{l}\text { Rha, Park, Song, } \\
\text { Lee, Lee/August } \\
2015\end{array}$ & $\begin{array}{l}\text { cross-sectional } \\
\text { descriptive } \\
\text { study }\end{array}$ & $\begin{array}{c}\mathrm{n}=227 \text { family } \\
\text { caregivers }\end{array}$ & Surveys & $\begin{array}{l}\text { no control } \\
\text { group }\end{array}$ & $\begin{array}{l}\text { - The Zarit Burden } \\
\text { Interview } \\
\text { - The caregiver's } \\
\text { QOL }\end{array}$ & $\begin{array}{l}\text { - Korean versions of } \\
\text { Zarit Burden Interview } \\
\text { - WHOQOL-BREF }\end{array}$ & $\mathrm{N} / \mathrm{A}$ \\
\hline $\begin{array}{c}\text { Ferré-Grau, } \\
\text { Raigal-Aran, } \\
\text { Lorca-Cabrera, } \\
\text { Ferré-Bergadá, } \\
\text { Lleixà-Fortuño, } \\
\text { Lluch-Canut, Puig- } \\
\text { Llobet and Albacar- } \\
\text { Riobóo/July } 2019\end{array}$ & $\begin{array}{l}\text { 3-month, } \\
\text { randomized, } \\
\text { controlled } \\
\text { trial }\end{array}$ & $\begin{array}{c}\mathrm{n}=108 \text { family } \\
\text { caregivers of } \\
\text { individuals with } \\
\text { chronic disease, with } \\
\text { a minimum four } \\
\text { months experience } \\
\text { as a caregiver }\end{array}$ & $\begin{array}{l}\text { smartphone app- } \\
\text { based intervention } \\
\text { to use over a period } \\
\text { of } 28 \text { days, which } \\
\text { offers different } \\
\text { activities from } \\
\text { Monday-Friday }\end{array}$ & $\begin{array}{c}\text { receive } \\
\text { standard } \\
\text { intervention }\end{array}$ & $\begin{array}{l}\text { - Baseline } \\
\text { assessment } \\
\text { - } 1 \text { month after } \\
\text { baseline } \\
\text { - } 3 \text { months after } \\
\text { baseline } \\
\text { - } 6 \text { months after } \\
\text { baseline }\end{array}$ & $\begin{array}{c}\text { - sociodemographic } \\
\text { questionnaire } \\
\text { - scale of positive } \\
\text { mental health } \\
\text { - scale of caregiver } \\
\text { burden } \\
\text { - questionnaire about } \\
\text { the use of technology } \\
\text { (Visit 1, experimental } \\
\text { group) } \\
\text { - questionnaire about } \\
\text { app satisfaction (Visit 2, } \\
\text { experimental group) }\end{array}$ & $\mathrm{N} / \mathrm{A}$ \\
\hline $\begin{array}{c}\text { Metin, } \\
\text { Karadas, Balci, } \\
\text { \&Cankurtaran/ } \\
\text { May } 2019\end{array}$ & $\begin{array}{l}\text { Descriptive } \\
\text { study }\end{array}$ & $\begin{array}{c}n=131 \text { older person } / \\
\text { caregiver dyads }\end{array}$ & & $\mathrm{N} / \mathrm{A}$ & & $\begin{array}{l}\text { - Older Adult } \\
\text { Information Form, } \\
\text { - Edmonton Family } \\
\text { Scale, } \\
\text { - Family Caregiver } \\
\text { Information Form } \\
\text { - Zarit Burden } \\
\text { Interview }\end{array}$ & $\begin{array}{l}\text { Fragility of } \\
\text { caregiving }\end{array}$ \\
\hline
\end{tabular}




\begin{tabular}{|c|c|c|c|c|c|c|c|}
\hline $\begin{array}{l}\text { Lindauer et al./May } \\
\qquad 2019\end{array}$ & $\begin{array}{l}\text { Intervention } \\
\text { study }\end{array}$ & $\begin{array}{c}\mathrm{n}=13 \text { family } \\
\text { caregivers of patients } \\
\text { with Alzheimer's } \\
\text { disease and related } \\
\text { dementias }\end{array}$ & $\begin{array}{l}\text { 8-week } \\
\text { videoconference } \\
\text { intervention (Tele- } \\
\text { STAR caregiver } \\
\text { education), } \\
\text { workbook the } \\
\text { caregivers filled out } \\
\text { during the week } \\
\text { (a revision of the } \\
\text { STAR-C workbook) }\end{array}$ & $\mathrm{N} / \mathrm{A}$ & $\begin{array}{l}\text { - Baseline } \\
\text { assessment } \\
\text { - } 4 \text { weeks after } \\
\text { baseline } \\
\text { - post-intervention } \\
\text { test ( } 8 \text { weeks after } \\
\text { baseline) } \\
\text { - } 2 \text { months after } \\
\text { intervention }\end{array}$ & $\begin{array}{l}\text { - Revised Memory } \\
\text { and Behavior Problems } \\
\text { Checklist } \\
\text { - Zarit Burden } \\
\text { Interview } \\
\text { - Desire to } \\
\text { Institutionalize, Revise } \\
\text { - QOLAD } \\
\text { - Montreal Cognitive } \\
\text { Assessment }\end{array}$ & $\begin{array}{l}\text { Family } \\
\text { caregiver } \\
\text { burden and } \\
\text { depression. }\end{array}$ \\
\hline
\end{tabular}

Keys: AAQ-II: Psychological Flexibility Acceptance and Action Questionnaire; BDI-II: Beck Depression Inventory; COPE: Carers of Older People in Europe; CQOLC: Caregiver Quality of Life Index-Cancer; EACQ: Experiential Avoidance in Caregiving Questionnaire; EQ5D: Euroqol Group, assesses quality of life; GAD-7: Generalized Anxiety Disorder; K10: Kessler-10 to assess psychological distress; QOLAD: Quality of Life in Alzheimer's Disease; S5:The 'Short Five' Personality Traits ; SOC-13: Sense of coherence; SPPB: Short Physical Performance Battery; SUS: System Usability Scale; WBSI: The White Bear Suppression Inventory; WHOQOL-BREF: World Health Organization Quality of Life-BREF

improvements in physical fitness were demonstrated for all research groups in comparison to the matched control groups, supporting the effectiveness of this educational program. VR technology was found as an entirely useful tool to engage adults with mild to moderate IDD, and some with severe levels of IDD, in a variety of activities by CGs from different educational backgrounds and professions [67].

\section{Effects of telehealth based intervention}

Linadauer et al. in a pilot study assessed the preliminary efficacy of a revised telehealth-based intervention (Tele-STAR) and the fidelity of Tele-STAR to the original caregiver intervention (STAR-C). The study concluded that the Tele-STAR intervention in this small sample reduced the burden on the RMBPC but did not improve on depression scores. Tele-STAR had good program and treatment fidelity to STAR-C. The fidelity assessment suggests that the Tele-STAR intervention adhered to the original STAR-C protocol and that it was implemented as designed. The implication of this fidelity assessment that the caregiver burden was reduced by the intervention and not by extraneous factors caused by divergence from the STAR-C program [68].

\section{STRENGTHS AND LIMITATIONS}

A comprehensive review has been included in the rationale and evidence for virtual methods of training for caregivers. We limited the systematic reviews to caregivers of adult patients with results. The systematic review only selected adult caregivers who were 18 years or older. Another limitation of this review is that the review included only those studies that used internetbased interventions, which possibly excluded other functional studies that had used non internet-based interventions.

\section{CONCLUSION}

Caregiver burden is a prevalent and costly concern. To date, no studies were identified on CGs burden of demanding diseases. Additional research is needed to establish the link between CGs burden and effective interventions using telehealth and web-based platforms. Given the safety of mind-body interventions, the cost-effectiveness of delivering these interventions, and that the outcomes of most studies suggesting their positive effects on risk factors associated with quality of life, virtual delivery could prove to be highly beneficial for CGs. Exposing CGs to virtual methods of training, both for the prevention and management of CG burden, has the potential of simultaneously addressing health concerns of CGs and their patients. This could significantly contribute to advancing scientific knowledge for better outcomes.

\section{ACKNOWLEDGEMENTS}

The authors would like to acknowledge Maya Seernani, Ria Shani, Rohan Shani, and Lauren Walter for their contributions to the paper.

\section{REFERENCES}

1. National Alliance for Caregiving and AARP. Caregiving in the U.S. 2015. http://www.aarp.org/content/dam/aarp/ppi/2015/caregivingin-the-united-states2015-report-revised.pdf.

2. Applebaum AJ, Breitbart W. Care for the cancer caregiver: A systematic review. Pall Supp Care. 2013;11: 231-52.

3. Bevans M, Sternberg EM. Caregiving burden, stress, and health effects among family caregivers of adult cancer patients. JAMA. 2012;307(4): 398-403.
4. Adelman RD. Caregiver burden: A clinical review. JAMA. 2014;311(10) 105260 .

5. Hiseman JP, Fackrell R. Caregiver burden and the non-motor symptoms of Parkinson's disease. Int Rev Neurobiol. 2017;133: 479-497.

6. Schulz R, Beach SR. Caregiving as a risk factor for mortality: the Caregiver Health Effects Study. JAMA. 1999;282(23): 2215-9.

7. Haines. Reducing stress and anxiety in caregivers of lung transplant patients: Benefits of mindfulness meditation. Int J Organ Transplant Med. 2014;5(2): 50-56.

8. Caqueo-Urizar A. Caregiver's quality of life and its positive impact on symptomatology and quality of life of patients with schizophrenia. Health Qual Life Outcomes. 2017;15(1): 76.

9. Metin ZG, Karadas C, Balci C, et al. The perceived caregiver burden among Turkish family caregivers providing care for frail older adults, J Transcult Nurs. 2018;30(3): 222-230.

10. Rohleder N, Marin TJ, Ma R, et al. Biologic cost of caring for a cancer patient: Dysregulation of pro- and anti-inflammatory signaling pathways. J ClinOncol 2009;27: 2909-15.

11. Amendola F, Oliveira MA, Alvarenga MR. Influence of social support on the quality of life of family caregivers while caring for people with dependence. Rev Esc Enferm USP. 2011;45: 884-9.

12. Song JI, Shin DW, Choi JY, et al. Quality of life and mental health in family caregivers of patients with terminal cancer. Support Care Cancer 2011;19: 1519-26.

13. Geng HM, Chuang DM, Yang F, et al. Prevalence and determinants of depression in caregivers of cancer patients: A systematic review and meta-analysis. Medicine (Baltimore). 2018;97(39): e11863.

14. National Alliance for Caregiving. Cancer care-giving in the U.S.: An intense, episodic, and challenging care experience; 2016.

15. Geng HM, Chuang DM, Yang F, et al. Prevalence and determinant of depression in caregivers of cancer patients: A systematic review and meta-analysis. Medicine (Baltimore). 2018;97(39): e11863.

16. Yang X, Hao Y, George SM, et al. Factors associated with health-related quality of life among Chinese caregivers of the older adults living in the community: A cross-sectional study. Health Qual Life Outcomes. 2012;10: 143 .

17. Zarit SH. Behavioral disturbances of dementia and caregiver issues. Int Psychogeriatr. 1996; 8(3): 263-8, 269-72.

18. Romito F. Informal caregiving for cancer patients. Cancer. 2013;119(11) 2160-9.

19. Northouse LL. Interventions with family caregivers of cancer patients: Meta-analysis of randomized trials. CA Cancer J Clin. 2010;60(5): 317-39.

20. Copley Cobb S. A comparison of the reactions of caregivers of patients with cancer versus patients with other chronic medical conditions. Oncol Nurs Forum. 2016;43(3): 321-7.

21. Williams AL. Family caregivers to adults with cancer: The consequences of caring. Recent Results Cancer Res. 2018;210: 87-103.

22. Northouse LL. The impact of caregiving on the psychological well-being 
of family caregivers and cancer patients. Semin Oncol Nurs. 2012;28(4): 236-45.

23. Maguire R. Worry in head and neck cancer caregivers: The role of survivor factors, care-related stressors, and loneliness in predicting fear of recurrence. Nurs Res. 2017;66(4): 295-303.

24. Bevans M, Sternberg EM. Caregiving burden, stress, and health effects among family caregivers of adult cancer patients. JAMA. 2012;307(4): 398-403.

25. Schulz R, Beach SR. Caregiving as a risk factor for mortality: The caregiver health effects study. JAMA. 1999;282(23): 2215-9.

26. Lee S. Caregiving and risk of coronary heart disease in U.S. women: A prospective study. Am J Prev Med. 2003;24(2): 113-9.

27. Gouin JP, Hantsoo L, Kiecolt-Glaser JK. Immune dysregulation and chronic stress among older adults: A review. Neuroimmunomodulation. 2008;15(4-6): 251-9.

28. Suzuki K, Tamakoshi K, Sakakibara K. Care-giving activities closely associated with the development of low-back pain among female family caregivers. J Clin Nurs. 2016;25(15-16): 2156-67.

29. Sharan D. Musculoskeletal disorders in caregivers of children with cerebral palsy following a multilevel surgery. Work. 2012;41(1): 1891-5.

30. Cho HJ. Sleep disturbance and depression recurrence in community dwelling older adults: A prospective study. Am J Psychiatry. 2008;165(12): $1543-50$

31. Ploeg J. Web-based interventions to improve mental health, general caregiving outcomes, and general health for informal caregivers of adults with chronic conditions living in the community: Rapid evidence review. J Med Internet Res. 2017;19(7): e263.

32. Budhrani-Shani P. Mind-body exercises for nurses with chronic low back pain: An evidence-based review. Nurs Res Pract. 2016;1-10.

33. Cho HJ. Sleep disturbance and depression recurrence in communitydwelling older adults: A prospective study. Am J Psychiatry. 2008;165(12): 1543-50.

34. Lavretsky H. A pilot study of yogic meditation for family dementia caregivers with depressive symptoms: Effects on mental health, cognition, and telomerase activity. Int J Geriatr Psychiatry. 2013;28(1): 57-65.

35. Lavretsky H, P Siddarth, MR Irwin. Improving depression and enhancing resilience in family dementia caregivers: A pilot randomized placebocontrolled trial of escitalopram. Am J Geriatr Psychiatry. 2010;18(2): 154-62.

36. Lengacher CA. Examination of broad symptom improvement resulting from mindfulness-based stress reduction in breast cancer survivors: A randomized controlled trial. J Clin Oncol. 2016;34(24): 2827-34.

37. Leung L. Mindfulness-based stress reduction (MBSR) as sole intervention for non-somatization chronic non-cancer pain (CNCP): Protocol for a systematic review and meta-analysis of randomized controlled trials. BMJ Open. 2015;5(5): e007650.

38. Zeng Y. Health benefits of qigong or tai chi for cancer patients: A systematic review and meta-analyses. Complement Ther Med. 2014:22(1): 173-86.

39. Bajaj JS. Mindfulness-based stress reduction therapy improves patient and caregiver-reported outcomes in cirrhosis. Clin Transl Gastroenterol. 2017;8(7): e108

40. Stjernsward S, L Hansson. Effectiveness and usability of a web-based mindfulness intervention for families living with mental illness. Mindfulness (N Y). 2017;8(3): 751-764.

41. Milbury K. Couple-based Tibetan yoga program for lung cancer patients and their caregivers. Psychooncology. 2015;24(1): 117-20.

42. Milbury K. Yoga program for high-grade glioma patients undergoing radiotherapy and their family caregivers. Integr Cancer Ther. 2017;1-5.

43. Kotronoulas G, Wengstrom Y, Kearney N. Alterations and interdependence in self-reported sleep-wake parameters of patientcaregiver dyads during adjuvant chemotherapy for breast cancer. Oncol Nurs Forum. 2016;43(3): 288-301.
44. Von Heymann-Horan AB. Dyadic psychological intervention for patients with cancer and caregivers in home-based specialized palliative care: The Domus model. Palliat Support Care. 2017;1-9.

45. Paré G, Moqadem K, Pineau G, et al. Clinical effects of home telemonitoring in the context of diabetes, asthma, heart failure and hypertension: a systematic review. J Med Internet Res. 2010;12(2): e21.

46. Kushner RF, KW Sorensen. Lifestyle medicine: The future of chronic disease management. Curr Opin Endocrinol Diabetes Obes. 2013;20(5): $389-395$.

47. Katrancha ED. Effects of a video guided T'ai Chi group intervention on center of balance and falls efficacy: A pilot study. Geriatr Nurs. 2015;36(1): 9-14

48. Dam AEH. Development and feasibility of Inlife: A pilot study of an online social support intervention for informal caregivers of people with dementia. PLoS One. 2017;12(9): 1-17.

49. Lauche R. Prevalence, patterns, and predictors of T'ai Chi and qigong use in the United States: Results of a nationally representative survey. J Altern Complement Med. 2016;22(4): 336-42.

50. Wu G, LM Keyes. Group tele-exercise for improving balance in elders. Telemed JE Health. 2006;12(5): 561-70

51. Wu G. Comparison of telecommunication, community, and homebased Tai Chi exercise programs on compliance and effectiveness in elders at risk for falls. Arch Phys Med Rehabil. 2010;91(6): 849-56.

52. Geng HM, Chuang DM, Yang F, et al. Prevalence and determinants of depression in caregiver of cancer patients: A systematic review and metaanalysis. Medicine. 2018;97(39): e11863.

53. Rha SY, Park Y, Song SK, et al. Caregiving burden and the quality of life of family caregivers of cancer patients: the relationship and correlates. European Journal of Oncology Nursing.2015;19(4): 376-382.

54. Duan J, Fu J, Gao H, et al. Factor analysis of the caregiver quality of life index-cancer (CQOLC) scale for Chinese cancer caregivers: A preliminary reliability and validity study of the CQOLC-Chinese version. PLoS One. 2015;10: e0116438.

55. McLean S, Chandler D, Nurmatov U, et al. Telehealthcare for asthma. Cochrane Database Syst Rev. 2010;10: CD007717.

56. Finkelstein J, Friedman RH. Potential role of telecommunication technologies in the management of chronic health conditions. Dis Manag Health Out. 2000;8(2): 57-63.

57. Northouse L, Williams A, Given B, et al. Psychosocial care for family caregivers of patients with cancer. J Clin Oncol. 2012;30: 1227-34.

58. National alliance for caregiving. Cancer caregiving in the U.S.: An intense, episodic, and challenging care experience; 2016.

59. Rietdijk R, Togher L, Power E. Supporting family members of people with traumatic brain injury using telehealth: A systematic review. J Rehabil Med. 2012;44(11): 913-921.

60. Samoocha D, Bruinvels DJ, Elbers NA, et al. Effectiveness of web-based interventions on patient empowerment: a systematic review and metaanalysis. J Med Internet Res. 2010;12(2): e23.

61. Paré G, Moqadem K, Pineau G, et al. Clinical effects of home telemonitoring in the context of diabetes, asthma, heart failure and hypertension: a systematic review. J Med Internet Res. 2010;12(2): e21.

62. Metin ZG, Karadas C, Balci C, et al. The perceived caregiver burden among Turkish family caregivers providing care for frail older adults. J Transcult Nurs. 2018;30(3): 222-230.

63. Kaskinen A, Ayeboa-Sallah B, Teivaanmäki T, et al. Pediatric web-based chat services for caregivers of children: Descriptive study. J Med Internet Res. 2018;20(12);e10165.

64. Lappalainen P, Pakkala I, Nikander R. Care ACT - internet-based intervention for enhancing the psychological well-being of elderly caregivers - a study protocol of a controlled trial. BMC Geriatrics. 2018;19(1): 72 .

65. Tan J, Lam KFY, Lim Kua EH, et al. Post-intervention sustainability of a brief psycho-educational support group intervention for family caregivers of cancer patients. Asia-Pacific Psychiatry. 2017;10(10): e12305. 


\section{Budhrani-Shani P, et al.}

66. Sahadevan S, Namboodiri V. Depression in caregivers of patients with breast cancer. A cross-sectional study from a cancer research center in South India. Indian J Psychiatry. 2019;61(3): 277.

67. Lotan M, Yalon-Chamovitz S, Weiss PL. Training caregivers to provide virtual reality intervention for adults with severe intellectual and developmental disability. J Phys Ther Educ. 2011;25(1): 15-19.

68. Lindauer A, Mincks K, Spoden N, et al. Using technology to facilitate fidelity assessments: The Tele- STAR caregiver intervention. J Med Internet Res. 2019;21(5). N.PAG. https://doi-org.ezp.twu. edu/10.2196/13599. 